\title{
Capturing developmental dynamics within a transdiagnostic framework: Challenges and promises
}

\author{
Duncan E. Astle ${ }^{1}$, Dani S. Bassett ${ }^{2,3}$ \& Essi Viding ${ }^{4}$
}

1. MRC Cognition and Brain Sciences Unit, University of Cambridge

2. Departments of Bioengineering, Electrical \& Systems Engineering, Physics \& Astronomy, Neurology, and Psychiatry, University of Pennsylvania

3. The Santa Fe Institute

4. Psychology and Language Sciences, University College London

\section{Abstract}

There is a growing body of research that seeks to understand the mechanisms that drive and maintain neurodevelopmental differences, without recourse to conventional diagnostic categories. So called 'transdiagnostic' studies change multiple design features, relative to a more conventional case-control design. Different sampling frames, approaches to assessment and analytic frameworks are allowing researchers to explore neurocognitive mechanisms across hitherto accepted diagnostic boundaries. Sensitive measurement, bridging levels of analysis, and capturing developmental change all pose significant challenges to transdiagnostic researchers. However, methods borrowed from elsewhere, allowing researchers to model individual-level data rather than the group average, and a new focus on developing circuits rather than singular brain regions, are bringing fresh mechanistic insights. We argue that a transdiagnostic approach needs to do more than just improve the characterisation of neurodivergent young people; in future it must also incorporate the developmental dynamics that capture how and when neurodevelopmental differences emerge. This crucial step will require methodological innovation. We introduce approaches that are just emerging within the field, which may allow us to do this, including Generative Network Modelling, Impulse Response Analysis, Network Control Theory and Normative Modelling. 


\section{The importance of developmental timing}

During neurodevelopment the brain undergoes a continual processes of adaptation, across multiple levels of analysis and many time scales. Each individual's brain adapts in response to the environment in which it develops and according to unique characteristics conferred by their genetic background. This complex process of adaptation starts early, even prenatally, and over time results in diverse trajectories of brain development, cognition, and behaviour. In other words, a continual adaptive ontogeny creates unique individuals, but also makes pinpointing moments of divergence between individuals extremely challenging. Establishing the specific mechanisms that drive that divergence is more challenging still. We can identify different trajectories by tracing observable and measureable characteristics, but the underpinning genetic and environmental factors that shape that adaptation are much harder to quantify.

An emergent property of these overlapping adaptive processes is the existence of 'sensitive periods' - epochs of more dramatic positive change during which capacities emerge rapidly. These periods can also be windows of potential vulnerability. For example the period between 6 months to 3 years of age has been identified as a sensitive period for the acquisition of oral language (Norrman \& Bylund, 2016), and adolescence has been identified as one sensitive period for the development of new social cognitive skills (Fuhrmann et al., 2015). The emergence of behavioural, learning and mental health difficulties also has a developmental context. Inattention and hyperactivity tend to first be recognised in early to middle childhood, with the majority of children who experience these externalising difficulties first being identified between the ages of 6 and 10 years (Sayal et al., 2018; Scahill \& Schwab-Stone, 2000). Difficulties with literacy and numeracy are often identified when children enter school, typically between ages 5 and 7 years (Bull et al., 2008). In contrast, difficulties with mood and anxiety most commonly first appear during adolescence (Kessler et al., 2010). These rough windows reflect population-level data, in reality, just as individuals are adapting to a unique combination of constraints, so developmental trajectories will vary considerably between individuals. 
Our understanding of the difficulties individuals encounter during development is currently constrained by diagnostic frameworks that chart a list of symptoms and assign individuals to one or more discrete categories at a particular point in time. Existing diagnostic classification systems, such as the DSM-5 (American Psychiatric Association ,2013)) or ICD-11 (World Health Organization, 2019) have been widely critiqued (Astle et al., 2021; Astle \& FletcherWatson, 2020; Happé et al., 2006; Pennington, 2006), with many scholars and practitioners questioning whether they are fit for purpose, in both research and practice. The purpose of this review is not to provide a detailed overview of the conceptual and methodological shortcomings of the diagnostic orthodoxy; this has already been done (Astle et al., 2021). To summarise the case against existing diagnostic systems briefly: these frameworks are thought to be ill equipped to accommodate the high degree of symptom overlap across diagnoses, incorporate variability within diagnoses, or capture the needs of those with difficulties that do not conform to a diagnostic standard. Our efforts to understand underpinning mechanisms or deliver effective support will inevitably be impeded by ill-fitting criteria - especially when the starting point for many studies is a cross-sectional case-control comparison.

The concerns about the existing diagnostic frameworks have led many to call for a shift towards a 'transdiagnostic' framework in which categorical boundaries are relaxed, redrawn, or removed altogether (Coghill \& Sonuga-Barke, 2012; Levy \& Ebstein, 2009; Sonuga- Barke et al., 2016; Sonuga-Barke \& Coghill, 2014). Broadly speaking this alternative framework focuses instead on the variability of particular characteristics within the population rather than on predefined categories and could be helpful when considering preventative, clinical staging models of care (McGorry \& Mei, 2021). In research settings, deployment of a transdiagnostic framework means that recruitment strategies are broadened and data-driven methodologies are applied, capturing dimensions (Astle et al., 2019) or clusters (Astle et al., 2019; Bathelt et al., 2021; Kushki et al., 2019; Siugzdaite et al., 2020) that provide parsimonious accounts of the variability within these more representative cohorts. In some cases these new data-driven accounts can be used to query the utility of existing diagnoses (Bathelt et al., 2018; Kushki et 
al., 2019), but more commonly they are used to bring fresh insight to the scope and nature of neurodevelopmental difficulties (Bathelt et al., 2021). A transdiagnostic framework also opens the door for a deeper conceptual shift. Abandoning the supremacy of diagnostic status shifts the emphasis to capturing the performance of an individual, regardless of their formal label. This shift allows us to focus on understanding characteristics that are impactful in daily life, whether they match a diagnostic prototype or not. In some respects, the shift also mirrors similar changes within the neurodiversity movement, which focuses on 'differences' rather than 'disorders', and resists the default pathologisation of young people, whilst recognising that some may experience difficulties that are profoundly disabling (Chapman, 2020).

The absence of developmental context from the existing diagnostic criteria is particularly troubling. The symptoms are treated as static. In reality the likelihood of any particular symptom characteristic or set of characteristics being either an enduring or sole defining feature of a person's condition across their entire development is slim (Caspi et al., 2020). We will struggle to identify the drivers of particular difficulties if we group individuals according to their cross-sectional diagnostic status, ignoring their vastly different profiles of strength and difficulty, or the developmental context in which those difficulties occur. Likewise, an intervention selected on the basis of a diagnostic label at a single time-point is unlikely to be optimally effective. Put simply, viewing developmental differences through a stationary diagnostic lens may not have served us well, either as researchers or practitioners. It may not be enough to simply revisit diagnostic boundaries; we also need to map and embrace the timing and sequencing of difficulties.

This paper takes as its backdrop the aspiration of a transdiagnostic approach, and attempts to provide a roadmap for its implementation within developmental science. Specifically, we argue that efforts to characterise the broad, mixed population of young people at neurodevelopmental risk using a transdiagnostic approach will fail if it does not incorporate the developmental dynamics that capture how difficulties emerge.

\section{Laying the foundations for transdiagnosticism}


There is no single design for a neurodevelopmental transdiagnostic study. Instead, different designs can provide different types of insight. Cross-group comparisons, in which multiple different diagnostic groups are recruited, can provide a simple way of testing whether developmental characteristics span existing boundaries (Kushki et al., 2019). However, these designs tend to recapitulate the problems of existing diagnostic frameworks, since they still use the established rubric for the recruitment and exclusion of participants. Alternative sampling techniques, such as functional recruitment on the basis of clinical or educational need (Holmes et al., 2019) are likely to yield samples more representative of neurodivergent young people, because they side-step the various biases, and exclusion criteria, inherent in the diagnostic system. Large-scale population representative cohorts, provided that the cognitive and behavioural measures are sufficiently rich, can also provide us with transdiagnostic insights (Bathelt et al., 2021). The ability to identify young people with particular characteristics, without their recruitment having been biased by those same characteristics, has the potential to redraw our understanding of the range, prevalence and complexity of developmental difficulties within the wider population. In short, the first consideration for a transdiagnostic study is to establish who is studied. Tethering recruitment more closely to the existing criteria will make the findings more directly relevant to the existing diagnoses; looser sample frames will likely achieve samples more representative of the real underlying population of young people experiencing difficulties.

Once the sample of interest is identified, the next ingredient for a transdiagnostic study is a set of measures to characterise that sample. Diagnostic studies tend to focus measurement heavily towards the characteristics thought most relevant for a particular group: Theory of Mind (ToM) assessments for studies of Autism, phonological awareness assessments for studies Dyslexia, inhibitory control assessments for studies of ADHD, and so on. This selective measurement can itself skew our understanding of the relevant characteristics for defining developmental difficulties. This fact is especially relevant when we consider that some cognitive or behavioural skills may 'gate-keep' others, a notion that we will cover in a 
subsequent section. For this reason transdiagnostic studies often cast a wider net, revealing that developmental difficulties are rarely as selective as previously thought.

The final key difference for a transdiagnostic study, relative to its diagnostic forebears, is the analytic toolkit. If group membership is loosened, or abandoned altogether, then we need methods that go beyond conventional univariate comparisons. To date, transdiagnostic studies have tended to adopt one of two alternative approaches. The first route is to use data reduction methods that identify broad dimensions of difference that characterise the sample. Multiple studies have shown that developmental difficulties can be well described as spanning a multidimensional space, with relevant dimensions including executive functioning (Boxhoorn et al., 2018; Pennington \& Ozonoff, 1996), phonological awareness (Bishop \& Norbury, 2002; Hulme \& Snowling, 2013), pragmatic language use (Bishop \& Norbury, 2002; Hawkins et al., 2016), inattention and hyperactivity (Haslam et al., 2006), and processing speed (Holmes, Guy, et al., 2021). The second route is to use data-driven clustering algorithms to identify subgroups of individuals. Like the first example, this is also essentially a data reduction technique, but it results in a novel data-driven grouping (Archibald et al., 2013; Bathelt et al., 2018; Kernbach et al., 2018). The clustering approach has the potential to challenge existing clinical boundaries, identify undocumented co-occurring difficulties, and provide an easy way to leverage alternative datatypes, thereby testing whether these novel groupings generalise to unseen data.

Changing these three design ingredients - recruitment, measurement and analytic tools enables the shift from a diagnostic to a transdiagnostic study (Figure 1). But, as we will see in the subsequent sections of this review, these changes are merely the first step. Placing a transdiagnostic approach within a developmental context, in which mechanisms and characteristics change with time, introduces additional challenges and opportunities. The challenges include the measurement of changing cognitive and behavioural functions with impure assessments. The opportunities include the potential to reveal how complex profiles of difficulty can emerge over time, as difficulties cascade. 


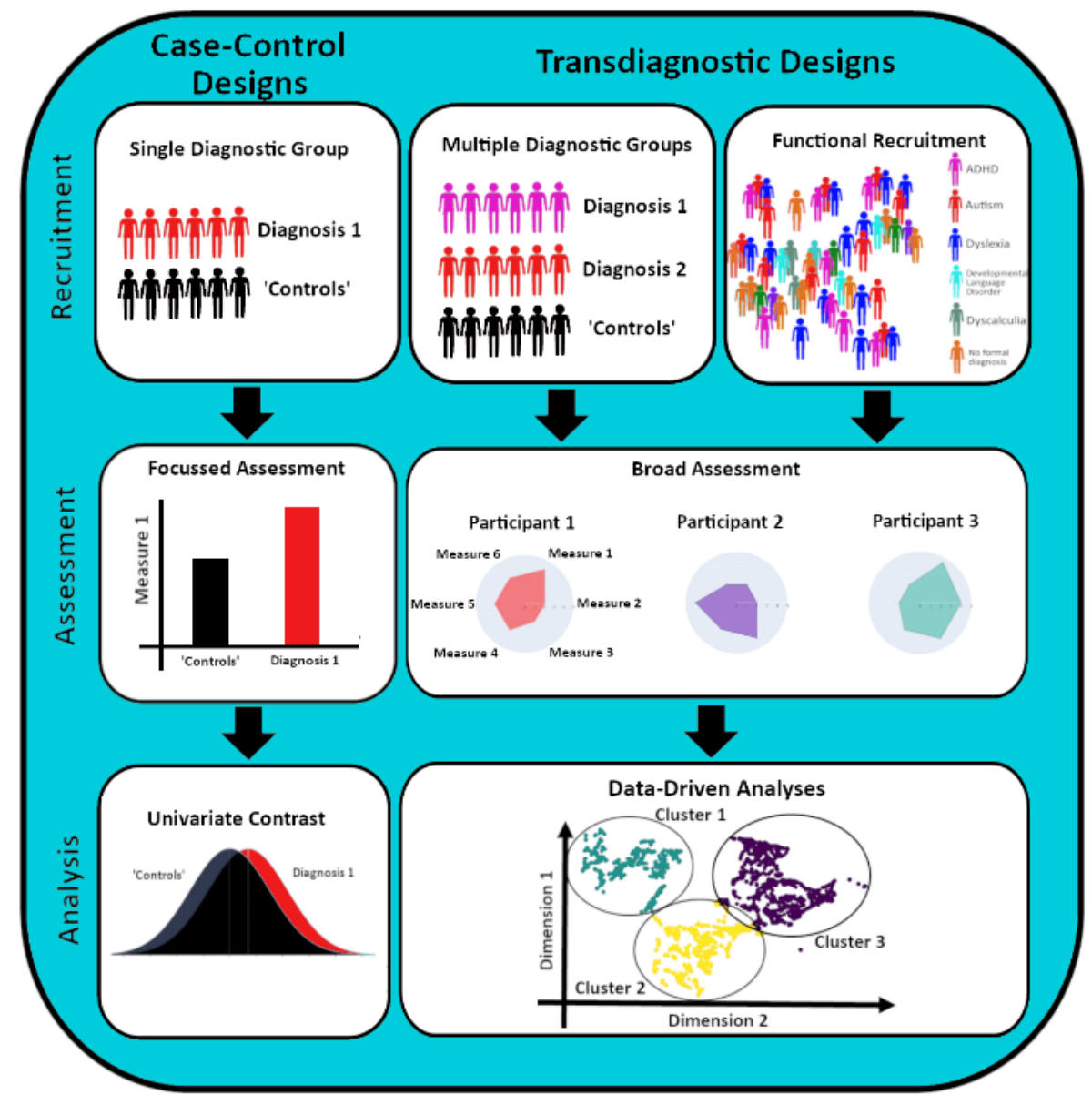

Figure 1: A schematic providing a contrast between the recruitment, assessment and analytic approaches typically deployed in case-control and transdiagnostic studies. Case-control designs typically recruit specific diagnostic groups and a separate 'control' group, assessment is typically focussed on a domain of interested, and the analytic approach typically contrasts groups on individual measures. Transdiagnostic designs can recruit multiple diagnostic groups, or have a functional sampling frame less tethered to the original criteria; the assessment is typically broader, attempting to capture a performance profile for each participant; and the analysis is often data-driven, attempting to establish either dimensions or clusters that optimally characterise the differences within the sample.

\section{Taking measurement seriously}

Our ability to track neurodevelopmental change, and identify when trajectories diverge, rests upon our ability to measure the relevant characteristics accurately and robustly. Here we raise two broad challenges to the measurement of behaviour and cognitive functions in a developmental context, and suggest possible ways of addressing them to progress the transdiagnostic study of neurodevelopment. These are: i) reliable and sensitive measurement of individual differences in cognition and behaviour; and ii) measurement of cognition and behaviour across different developmental periods. Clearly these are not the only two 
challenges we might focus on, but they represent central puzzles that we need to resolve as we attempt to capture neurodevelopmental dynamics.

Reliable and sensitive measurement of individual differences in brain and cognitive function:

Many well-established tasks from the cognitive neuroscience and experimental psychology traditions have poor psychometric properties, including poor test-retest reliability (Elliott et al., 2020; Enkavi et al., 2019; Parsons et al., 2019). This is perhaps not surprising. These tasks stem from a research tradition not originally focused on understanding individual differences, but instead concerned with detecting "species universals"; that is, how people perform a particular cognitive operation 'on average'. Indeed, much of our understanding of how a specific cognitive process develops stems from tasks designed with trial types that require different component processes, with the performance differential between those trial types being used as an index of that cognitive process. This within-subject subtraction approach is powerful, and has been used, for example, to explore developmental improvements in executive processes like set switching (Cepeda et al., 2001), working memory (Burnett Heyes et al., 2012) and inhibitory control (Cragg \& Nation, 2008). However, tasks optimised to capture sometimes subtle between-trial effects at a group level do not automatically lend themselves to reliably and sensitively measuring individual differences. Put simply, reliable within-group experimental effects can arise from unreliable between subject measurements (Fröhner et al., 2019). Tasks we like as experimentalists, designed to carefully tease apart different component processes, are unlikely to be optimally informative for understanding the differences between individuals. Indeed, experimental tasks are often chosen explicitly to minimise those differences.

A related obstacle is the 'single-shot' nature of most cognitive performance metrics. In contrast to questionnaire measures, which call upon the respondent to estimate particular characteristics based on multiple exposures over a period of time (e.g., "in the last year, how often..."), task-based neuroimaging or experimental psychology paradigms typically sample behaviour on a single occasion (albeit with multiple trials). This sort of sampling will limit the 
ability of the metric to capture enduring characteristics of an individual, and increase the effect of stochastic performance-influencing factors. In other words, it is hard to capture the 'trait' (as opposed the 'state') with a single static metric.

Together, these constraints will limit the utility of current cognitive neuroscience and experimental psychology paradigms, if the goal is to quantify transdiagnostic, trait-like neurocognitive mechanisms. The insensitivity of current assessments to individual and temporal variability will naturally hamper efforts to incorporate measures of cognition and behaviour with other indices to advance multi-level study of individual differences in neurodevelopment. Transdiagnostic studies often deploy data-driven analytic tools, which attempt to partition variance in performance to establish dimensions, or to partition participants to identify clusters. The intention is that these dimensions or clusters will optimally capture individual differences in the cognitive or behavioural domains of interest. However, they can sometimes capture extraneous sources of variance instead. For example, between-task variance can be impacted by when the testing battery a particular measure is scheduled. Tasks appearing just before a break, or at the end of the testing session, can appear more correlated because the child is tired. Likewise, tasks can appear more correlated if they all use the same performance metric, such as reaction time, accuracy, or between-trial error rate. These important sources of variance can heavily influence the dimensions or clusters we identify or our interpretation of them.

There are a number of ways in which researchers are already beginning to establish how we can better index individual differences in performance. For example, researchers have used staircasing procedures to more sensitively capture individual differences in task performance (Witton et al., 2017) and may sample task performance on different days or at different times of the same day, to extract trait-like features of task performance (Leonard et al., 2021; LydonStaley et al., 2020; McGowan et al., 2022; Swift \& Peterson, 2018). Other groups are using innovations in personal technology to sample behaviour at multiple time points (Chen et al., 2015; Kovac et al., 2016; Lydon-Staley et al., 2019). These high density performance 
measures can then be combined with traditional psychometric testing to estimate the relationship between static one-time assessments and daily or weekly fluctuations in performance.

Measurement across different developmental periods:

Related to the challenge above, but perhaps more particular to the developmental context, measurement sensitivity of a particular task is likely to change dramatically across infancy, childhood and adolescence. Furthermore, the same measure can draw on different processes at different developmental stages. This is a particular example of the 'task impurity problem' (Hartung et al., 2018). Poor choice of measures can thus give the false appearance of developmental change, or conversely can mask genuine change. To provide an example, Simpson-Kent and colleagues (Simpson-Kent et al., 2020) used a wide battery that could be broadly characterised as capturing both 'fluid' and 'crystallised' cognitive abilities, in a sample from age 5 to 18 years. Vocabulary assessments are usually labelled as a measure of crystallised performance, because the assessment is designed to tax the participant's existing word knowledge. However, the authors demonstrated that the inter-individual variability captured by the assessment varies with age. Using SEM-Trees (Brandmaier et al., 2013), a method that can partition structural equation models according to the measurement invariance, they established that in children under 9 years of age vocabulary predominantly captures variance associated with fluid measures (e.g., spatial working memory, matrix reasoning), and only from 9 years onwards does it predominantly capture variance associated with crystallised measures (e.g., literacy). In short, despite being a standardised validated measure, it appears to tax different aspects of cognition at different points in development. The above example both illustrates the challenge and its potential solution. Capturing multiple measures, and then modelling their interrelationships, can provide insight as to what is being measured and how this measurement sensitivity may change across individuals. In the example above, the aspects of cognition being taxed by the task change with age - for younger children the vocabulary measure draws upon fluid reasoning skills. 
In short, there is dearth of work validating paradigms to assess individual differences in a particular neurocognitive function across the lifespan, or across the ability spectrum. There are some solutions, like collecting broader sets of measurements and modelling interrelationships, but even these solutions have their limits - partly due to the construction of current experimental tasks and to the lack of data on the most appropriate ways of measuring particular constructs over development.

\section{Cognitive and behavioural 'gate keepers'}

As highlighted in the previous section, age can act as a moderator variable, shifting the target of an assessment. In other contexts the moderator could be a different aspect of cognition itself. This becomes increasingly important as we try to accurately capture a range of neurodevelopmental profiles. Take as an example verbal working memory - the ability to hold in mind and manipulate phonological information for brief periods of time (Gathercole et al., 2004). Tasks probing this cognitive function could measure something different in children with a phonological awareness difficulty (Holmes et al., 2015). In this example, one cognitive function (phonological awareness) may 'gate keep' another (working memory). The working memory assessment relies upon accurate phonological representations in order to sensitively measure the higher-order executive elements of working memory. If a participant cannot form good phonological representations, then the task may cease to be a good measure of their working memory.

This 'gate keeping' phenomena can itself reflect a cognitive system self-organising over time. Consider again verbal working memory as an example. Because tasks like this recruit multiple component processes that depend upon one another for task performance, this can itself come to shape neurocognitive development. Difficulties in verbal working memory tasks have been implicated across a wide-variety of neurodevelopmental disorders, including ADHD (Holmes, Guy, et al., 2021), autism (Williams et al., 2005) and dyslexia (Majerus \& Cowan, 2016). However, because there are multiple cognitive components that contribute to performance, there are different reasons why a child might find this task hard. Studies with 
more inclusive recruitment criteria and a broad battery of cognitive tasks reveal that verbal working memory difficulties are common both in children with a wider executive function difficulty (alongside difficulties in spatial working memory, fluid reasoning etc.), and in children with relatively good executive function skills but poor phonological processing (alongside difficulties in phonological awareness and verbal short-term memory) (Astle et al., 2019). In short, just like one cognitive domain might 'gate keep' another, when this is allowed to playout over development, difficulties can cascade. If enough gate keeping happens over time, then it constrains the development of other processes, and in turn shapes how the cognitive system organises itself (Karmiloff-Smith, 2009). To use the language of adaptation, difficulties within one aspect of functioning will shape how others develop.

This constructivist perspective, in which cognitive processes are inter-dependent, and this inter-dependence in turn shapes cognition across development (Karmiloff-Smith, 1994), presents both challenges and opportunities within a transdiagnostic framework. Cognitive or behavioural difficulties are unlikely to remain selective across the course of development. For example, early difficulties in hyperactivity may shape emerging pragmatic language skills (Hawkins et al., 2016), which in turn may shape wider social skills and elevate risk of peer rejection (de Boo \& Prins, 2007). Population-level cohorts, provided they have sufficiently rich data, may provide an ideal way of exploring these cascades. Whilst not traditionally considered transdiagnostic, these studies could provide invaluable prospective longitudinal data, sometimes since birth, that demonstrate how complex profiles of relative strength and difficulty in late childhood and adolescence could reflect cascading differences over many years. The challenge is to create longitudinal cohorts that indeed have that breadth of assessment over time.

Some transdiagnostic accounts of cognition and behavioural difficulties already implicitly incorporate this inter-connectedness. For example, psychopathology can be hierarchically organised, with more specific difficulties being organised under three broad categories namely internalising, externalising, and psychotic difficulties. In turn these categories 
converge on a single common dimension, termed 'p' (Caspi et al., 2014; Kotov et al., 2017). This conceptualisation provides a parsimonious account of psychopathology within both adults (Ruggero et al., 2019), and broad mixed samples of children at neurodevelopmental risk (Holmes, Mareva, et al., 2021). An often levelled critique of this model is that it reflects psychometric convenience, rather than any theoretical account of how these different difficulties can become nested. Nonetheless, the hierarchical nesting of difficulties is highly consistent with the constructivist account outlined above, in which the interconnectedness of behaviour and cognition means that differences cascade over development.

Regardless of whether we conceptualise cognition and behaviour processes as hierarchically nested or not, their interconnectedness means that difficulties at one particular level can arise from different causal routes at lower levels, a notion commonly termed equifinality (Bishop, 1997; Cicchetti \& Rogosch, 1996). One of the key demonstrations that makes the case for transdiagnosticism - that some common behavioural or cognitive characteristics appear to arise in supposedly distinct diagnostic groups - may itself reflect equifinal developmental mechanisms. Put simply, certain symptoms are common because they can be arrived at via multiple causal routes, just like verbal working memory difficulties emerge as part of multiple profiles (Astle et al., 2019).

\section{Bridging multiple levels of analysis}

We have so far focussed on challenges and opportunities for cognitive and behavioural assessment, as we place a transdiagnostic framework within a developmental context. These challenges and opportunities are amplified when trying to integrate assessments with other datatypes, such as neuroimaging data. Just like performance on any single task can be shaped by multiple underlying processes, so too any correlation between a particular brain region and performance could arise for different reasons. This fact is in part because just as the sensitivity of a cognitive assessment might vary across individuals and ages, as noted in 
the previous section, the functional role of neural circuits themselves change across development. Multiple theoretical perspectives agree that the functional specialisation of particular brain regions or circuits is not deterministic, but instead emerges probabilistically (Fair et al., 2007; Johnson, 2000, 2011; Jones et al., 2021). That is, the functional role of any neural assembly is shaped gradually over developmental time, and in part this shaping depends upon the connectivity of that assembly, in particular its inputs (Gottlieb, 2007, 2005). Likewise, cognitive processes do not simply come 'online' when a neural circuit matures. Instead nascent functional circuits support emerging cognitive processes, and as they are engaged in the service of those processes this repeated co-activity will itself shape future functional specialisation (Johnson, 2011). Put simply, relationships between brain and behaviour are not static. Their adaptive nature means that they will shape one another over development. This theoretical stand point seems at odds with discoveries of particularly strong relationships between individual brain regions or circuits and particular behaviours of task performances (Kowalczyk et al., 2021). If functional roles are shaped by interactions with other regions then how can individual isolated regions or circuits be so strongly linked with individual tasks or behaviours? These apparently simple relationships are however often the consequence of the selection of cognitive measures, issues with power, region of interest selection or no hold-out cross-validation. A recent analysis of the ABCD dataset using Canonical Correlation Analysis (CCA) tested the impact of sample size on the reliability and strength of univariate brain-behaviour relationships (Marek et al., 2020). In held out samples reliable estimates of the relationship between cortical thickness and a general cognitive factor only emerged at $\mathrm{N} \sim 2000$, and the strength of that reliable relationship was $d=0.15$. In other words, overfitting is common and small sample sizes can give the impression of strong relationships that are in fact inflated by sampling error.

We are not the first to outline the challenges described in this section (e.g., Karmiloff- Smith, 2010; Lessov-Schlaggar et al., 2016). The field is broadly aware that we tend to rely on individual measures to establish univariate brain-behaviour relationships, when in reality we 
are assessing a highly interconnected system that is changing dynamically with time, with those brain-behaviour relationships also likely changing. Despite this challenge being articulated previously, progress towards redressing it has been slow. Here are some ingredients for future progress:

1. Shared datasets that afford analyses at scale. New larger datasets that are both population representative (e.g., ACBD, Karcher \& Barch, 2021) and selectively sampling children at neurodevelopmental risk (e.g. CALM, PDN) afford more than just additional power. The larger sample size means that we can run analyses on a training sample while holding out a testing or replication sample. This capacity is important because many contemporary analytic tools, such as CCA or Partial Least Squares (PLS) risk over-fitting. The ability to test whether relationships between neural measures and behaviour generalise to unseen data is crucial.

2. Mapping relationships between complex aspects of neurobiology and cognition or behaviour could benefit from methods used elsewhere. For example, Hierarchical MIMIC Models have been adapted to incorporate structural neuroimaging data alongside multiple behavioural or cognitive assessments (Kievit et al., 2016). These are ideal for longitudinal data, because they allow the researcher to track developmental changes across multiple levels, whilst allowing the relationships between levels to also change with time. There is often an understandable reluctance to embrace new methods, because there is sometimes a perception that the method itself can become the focus, rather than the conceptual question. In reality the conceptual thinking and methodology must go hand-in-hand. If our methods are only able to capture simple pairwise relationships, then any subsequent theoretical model of brain-behaviour relationships will be similarly constrained.

3. The next generation of scientists need a broad training. There are inevitable limits in how many domains we can be expert in, but being unable to speak a 'common language' with others who work in adjacent fields makes it hard for us to borrow 
methods and approaches from elsewhere, or to integrate across different levels of analysis.

4. Interdisciplinary funding. Whilst many research funders advocate and encourage interdisciplinary proposals, the reality is that interdisciplinary projects are the hardest to fund. The dearth of interdisciplinary funding arises because reviewers tend to be harsher on projects that sit between disciplines rather than being firmly rooted within a single field, in part because reviewers' expertise tends to be squarely within a particular field and its established empirical approaches (Shapiro, 2014). This reviewer bias reduces the success of interdisciplinary proposals and disincentivises the borrowing of tools and methods from other fields.

\section{From groups to individuals: at what level to build models?}

Throughout this review we have emphasised that development is not merely a process of maturation, but an adaptation to a set of constraints unique to each individual. However, much of what we know about cognitive development comes from studying groups, not individuals. The benefits of the 'group average' approach are somewhat obvious: with such a degree of variability across individuals, in addition to substantial measurement noise in the majority of our assessments, averaging is essential for establishing reliable relationships between

different measures. The group average approach is how we know that working memory capacity linearly increases with age up to around 14 year and that the component structure of working memory is broadly stable from 4 to 15 year (Gathercole et al., 2004), that there is a developmental mismatch between our ability to orient attention to internal versus external representations (Shimi, Kuo, et al., 2014; Shimi, Nobre, et al., 2014), and the developmental time course of inhibitory control during middle childhood (Cragg et al., 2009). So much of what we know about neurocognitive development comes from the performance of large groups of individuals averaged together and then compared across ages. 
If the majority of our knowledge of neurocognitive development stems from a group-average approach, then the same is true for our knowledge of neurodevelopmental conditions. We typically Identify children with a particular diagnostic label, group them and compare groups on a host of neural and cognitive measures. A significant difference on a measure is then thought to reflect the underlying 'core deficit' that gives rise to the wider diagnostic phenotype. This logic has given rise to the majority of our theoretical accounts of neurodevelopmental conditions, from the Theory of Mind 'deficit' account of Autism (Baron-Cohen, 1995) to the executive function deficit theory of ADHD (Willcutt et al., 2005). However, this logic has been widely critiqued (Bishop, 1997; Happé et al., 2006; Pennington, 2006). Moreover, these theories have been notoriously difficult to validate empirically. Deficits apparently 'core' to a particular condition are often present among other groups, so they are not nearly as distinctive after all; not all individuals with a particular diagnosis have the supposed deficit, so they are not nearly so shared as previously thought; and they typically fail to account for the wide range of differences seen across individuals with the same diagnostic label (see Astle \& FletcherWatson, 2020 for a review).

These theories are a direct consequence of group averaging; that is of grouping according to diagnosis and using group average difference to inspire a theory of that particular diagnostic entity. As an explanatory framework this has regularly proven to be a conceptual dead end. The critique is highly overlapping with that of the diagnostic framework in which those theories are situated. Neither the labels, nor their associated theories, can capture the variability within a category, explain the characteristics that are commonly shared across supposedly distinct categories, or illuminate the co-occurrence of difficulties (see Astle et al., 2021 for a review). The same logical problem applies to the hunt for neural correlates of different disorder categories. Grouping individuals according to diagnostic status and comparing neural characteristics voxel by voxel, in the hunt for the 'neural seat of [insert diagnosis]', has yielded remarkably inconsistent results. For example, ADHD has been associated with differences in grey matter within the anterior cingulate cortex (Amico et al., 2011), caudate nucleus (Onnink 
et al., 2014), pallidum (Frodl \& Skokauskas, 2012), striatum (Greven et al., 2015), cerebellum (Mackie et al., 2007), prefrontal cortex (Dirlikov et al., 2015), premotor cortex (Mahone et al., 2011), and most parts of the parietal lobe (Shaw et al., 2006). The variety of brain regions identified is itself not problematic; we might expect group differences to be distributed. More troubling is the difficulty in replicate group average differences across studies. Indeed, a recent meta-analysis of almost 2000 participants found no consistent significant functional connectivity differences between ADHD participants and controls (Figure 2; Cortese et al., 2021).
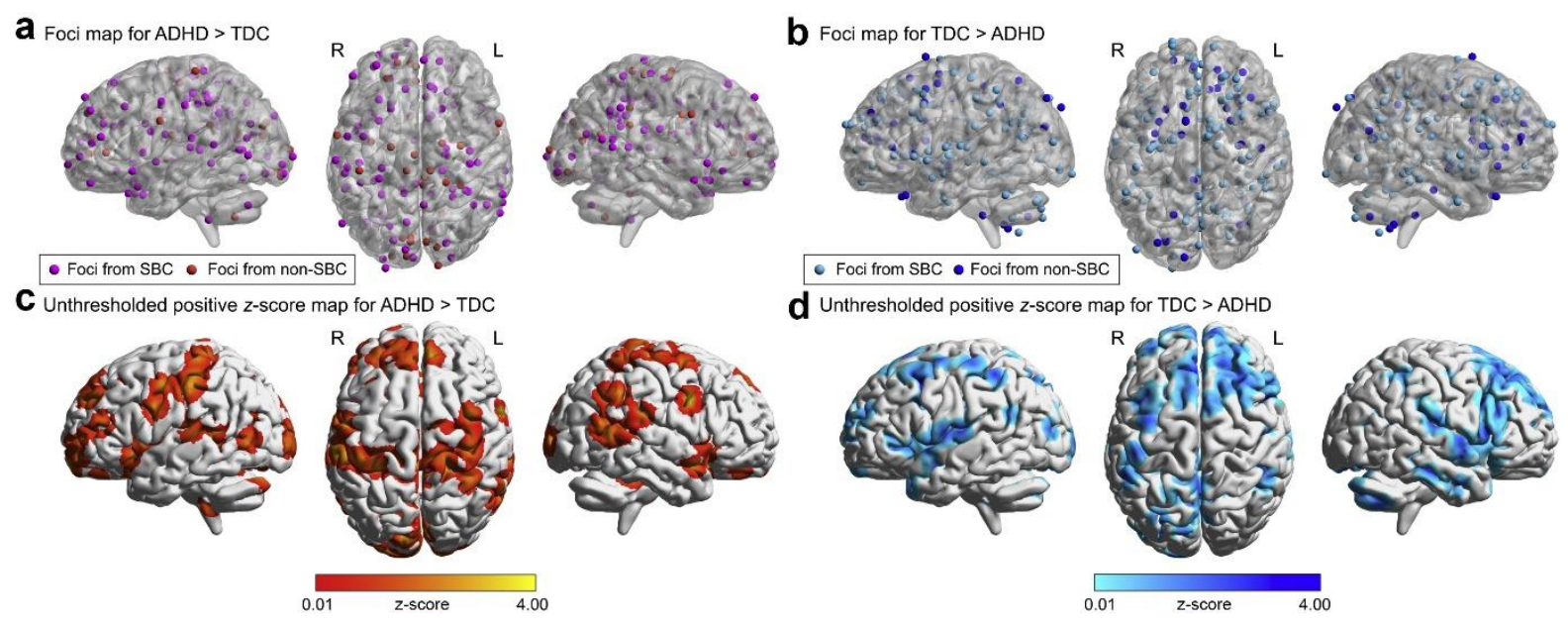

Figure 2: Taken with permission from Cortese et al. 2021. Foci with hyperconnectivity in attentiondeficit/hyperactivity disorder ( $A D H D$ ) reported in seed-based connectivity (SBC) studies and non-SBC studies are shown in purple and red, respectively (a). Foci with hypoconnectivity in ADHD reported in $S B C$ and non-SBC studies are shown in light blue and dark blue, respectively (b). Unthresholded positive z-score maps are shown for hyperconnectivity (c) and hypoconnectivity (d). $L=$ left; $R=$ right; $T D C=$ typically developing controls.

If our understanding of neurodivergent profiles is largely informed by group averaging then what are the alternatives? As we place developmental disorders within a transdiagnostic framework, there are many recent computational advances that could provide an alternative methodological, and in turn conceptual, approach, relative to conventional group comparisons. The first example is Hierarchical Bayesian Modelling (HBM; McGlothlin \& Viele, 2018). This family of models allows the researcher to separate and estimate parameters at multiple levels, thereby characterising the learning of an individual. For instance, it is possible to model how 
individuals learn about the likelihood of different stimuli being presented under different conditions. Because the model is fit to the individual, the researcher can in principle disentangle the potential influence of different sources of information in that learning process. The combination of this type of modelling with carefully designed behavioural paradigms, in which those sources of information are varied systematically, provides a formal way of characterising the underlying processes by which individuals integrate that information as they perform the task (e.g. Lawson et al., 2017). Individual-level model parameters can then be linked with other datatypes, such as neuroimaging (Hauser et al., 2014) or pupillometry (Lawson et al., 2017). A full review of the application of HBM is beyond the scope of the current review, moreover, there are likely multiple other methods that would do just as well. The crucial ingredient for our purposes is that this method provides mechanistic insight into behaviour without recourse to group average performance. A second example methodology is 'idiographic symptom networks'. These are an extension of more commonly used group level network science, in which nodes correspond to particular measures and the edges between them correspond to the partial relationships between them (Dalmaijer et al., 2021). Network analysis, when applied to the group, provides a way of mapping the interactions between multiple symptoms simultaneously (Dalmaijer et al., 2021). The application of graph theory can provide a way of characterising the organisational properties of that network, such as whether particular nodes act as hubs, connecting other more disparate symptoms. Where there is sufficiently rich data available for a given individual, these networks can be computed at the level of an individual (Fisher et al., 2017; Howe et al., 2020; Lydon-Staley, Leventhal, et al., 2021; Piccirillo \& Rodebaugh, 2019). This provides a means of building a model that characterises the temporal relationships between measures at the level of the individual. A third and final example we provide is Generative Network Modelling (GNM) (Betzel et al., 2016; Kaiser \& Hilgetag, 2004; Vértes et al., 2012). This is a biophysically grounded computational framework in which the formation of functional (Vértes et al., 2012) or structural connectome (Akarca et al., 2021) is simulated for a given individual (Betzel \& Bassett, 2017). Within the generative model connections form probabilistically reflecting the trade-off between 
the energetic cost of forming that connection and the topological value that the connection would yield. This framework allows the research to formalise different theoretical accounts of the basis upon which networks form over developmental time, and then implement, test, and refine those models. Crucially, this simulation can occur at the level of an individual's connectome, meaning that each simulation is unique to that person. This is achieved by individually calibrating the relative trade-off between the components of the generative model. Recent work has used this approach to show that each brain forms a network according to a subtly different economic trade-off (Akarca et al., 2021). These subtle differences cascade and amplify over development to produce the large amount of variability in connectome organisation that we see in children at neurodevelopmental risk. This approach is currently constrained by its relative biological plausibility - whilst it is biophysically embedded, the networks only form one connection at a time. Future changes will need to shift this framework to capturing more realistic weighted changed within networks. Nonetheless, the approach provides another example of how we can model and understand developmental processes without recourse to group averaging.

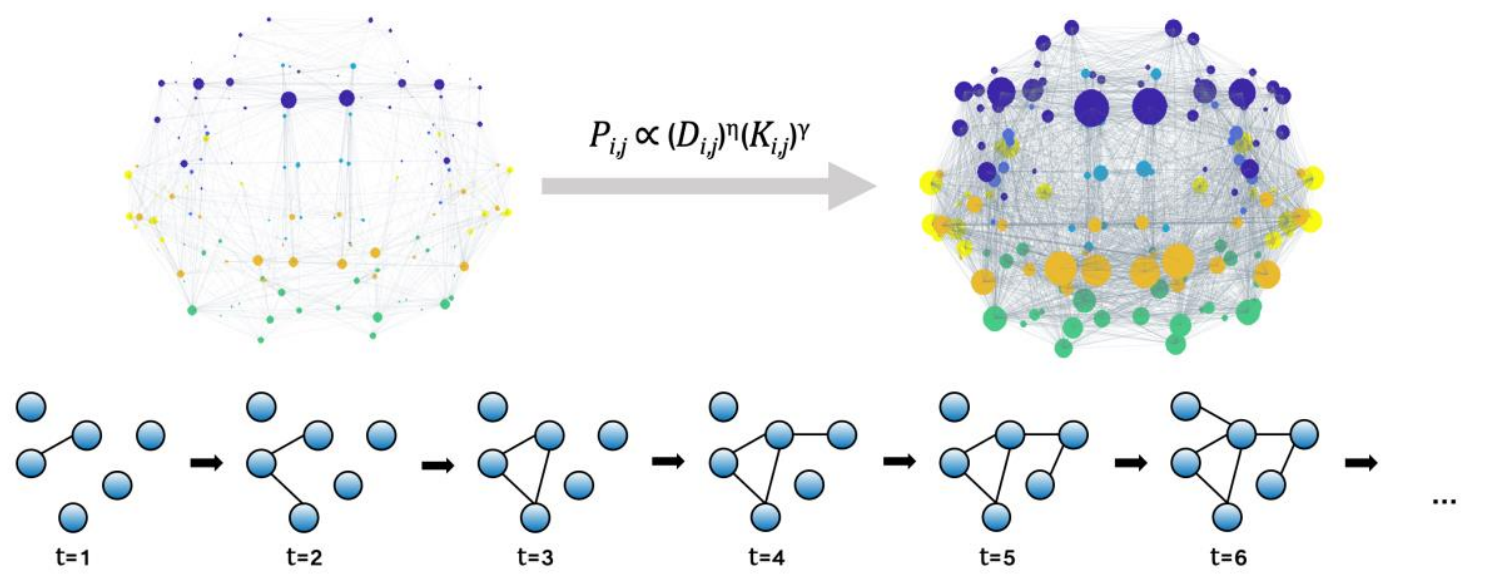

Figure 3: A simple wiring equation simulates the formation of a connectome within a Generative Network Modelling framework. The probably $(P)$ of nodes $i$ and $j$ connecting reflects the trade-off between the costs of those connections forming $(D)$ and the topological value that a connection would confer $(K)$. This simulates the formation of complex networks via the iterative addition of individual connections. 


\section{Beyond individual brain regions}

While the group average hampers understanding of the individual person, the focus on individual brain areas hampers an understanding of the emergent dynamics only possible from a group of brain areas. Hence, while drilling down from the sample to the single human, we must simultaneously expand upward, from the individual brain region to the circuit and connectome. This expansion hues more closely to the nature of cognition and behaviour, which together arise from the complex system of the brain-body union. That tighter connection, between method and the nature of the object of study, presages a greater potential for fundamental understanding, but also requires increasingly careful development of practical tools and notional structures, from algorithms to theory. As noted in a previous section, our methodological approach and conceptual framework must go hand-in-hand.

The recognition that complex systems like the brain cannot be explained by their separate components has gained momentum over recent years (Bassett \& Gazzaniga, 2011; Bullmore et al., 2009). The associated progress in approaching neuroimaging data from the complex systems' perspective has benefited greatly from the near simultaneous development and expansion of network science (Newman, 2010). A relatively young scholarly field of study, network science saw its first formal institutes around the year 2000, and its first undergraduate and graduate degrees about ten years later. Spanning from models and data analytics to conceptual frameworks, network science studies (and formalizes the study of) complex systems composed of many interacting parts. Of particular interest are such systems in which the pattern of part-to-part interactions is critically important for the observed function. $A$ counterpoint to reductionist thinking, network science stems from the acknowledgement that the ability to isolate and understand simple units does not imply the ability to start from those units and reconstruct the system. Rather, one must understand how the parts are related, and how those relations both constrain and support system processes.

The approach is particularly relevant to our focus here, as the study of neurodevelopmental differences has historically relied on unit-level models, which have precluded holistic 
understanding. Specifically, neural correlates of such differences have typically been evaluated through the lens of a long-standing model from adult neuropsychology, in which damage to an established brain unit can result in a specific profile of difficulties (Bishop, 1997). Neurodevelopmental differences do not fit well with this model for two key reasons. First, such differences do not reflect differences in individual brain regions. No single brain area underpins inattention or hyperactivity, or poor working memory (Siugzdaite et al., 2020). In fact, more broadly, the map from unit to difficulty profile (or vice versa) is not one-to-one: several units are implicated in a single difficulty, and a single unit is altered across many difficulties. This many-to-many map between region and difficulty calls for a connectivity-based approach. Second, neurodevelopmental differences emerge across time as the system engineers itself (Gottlieb, 2007). They arise on the backdrop of a time-evolving set of interactions between brain regions, between brain and behaviour, and between behaviours. Understanding the provenance of these difficulties, and targeting effective intervention, hence requires an understanding of network dynamics across brain and behaviour.

In what follows, we will briefly describe approaches that expand the study of neurodevelopmental differences beyond the model of adult neuropsychology, and in a manner that foregrounds emergence across brain networks and across time.

\section{Emergence across brain networks}

Approaches that expand beyond single brain regions to better understand the neural dynamics that accompany neurodevelopmental differences span from descriptive to predictive network approaches. Descriptive network approaches typically use graph metrics to quantitatively map variation in the architecture of connectivity patterns (Rubinov \& Sporns, 2010). Such approaches have elucidated links between variation in network topology and variation in cognition and symptomatology (Chu-Shore et al., 2011; Parkes et al., 2020; Zhang et al., 2021). More recently, predictive network approaches have focused in on how activity in one or a few brain regions can predictably drive changes in other brain regions. Two key examples include the finite impulse response approach (Blaauw et al., 2017; de Zwart et al., 2005) and 
network control theory (Lynn \& Bassett, 2019). Impulse response analysis uses the pattern of connections between regions to predict the degree to which a change in the activity of region $i$ (i.e., an impulse) will drive a change in the activity of other regions $j$ (i.e., a response) (LydonStaley, Cornblath, et al., 2021). The approach has proven useful in distinguishing regional influence on task-based fMRI activity in conditions ranging from schizophrenia to $22 \mathrm{q} 11.2 \mathrm{ds}$ (Cornblath et al., 2021; Woodward et al., 2015), and in cognitive processes ranging from working memory to emotion discrimination (Goghari et al., 2017; Sanford et al., 2020). Moreover, the approach has also shown extensive utility in predicting activity flow in a second kind of network—state networks, where single states, emotions, behaviours, or symptoms are represented by network nodes and where inferred causal relations between nodes are represented by network edges. In this context, impulse response analysis has been used to pinpoint influential emotions and symptoms, and their temporal dynamics, in depression, anxiety, and tobacco withdrawal (Bos et al., 2018; Lydon-Staley, Leventhal, et al., 2021; Yang et al., 2019).

A step beyond impulse response models, network control theory expands the question of interest from "How does a single unit drive change in the system?" to "How can time-varying changes in multiple units predictably drive the system to a desired state?". Network control theory provides a model, analytic solutions, and associated algorithms to answer this question, and has been quite broadly developed and applied across mechanical, robotic, technological, physical, and biological systems (Cornelius et al., 2013; Liu et al., 2011; Pasqualetti et al., 2014; Ruths \& Ruths, 2014). In the context of the brain, network control theory has been used to determine how the development of brain connectivity constrains (and supports) the attainment of an increasingly diverse dynamical repertoire (Tang et al., 2017); how individual differences in that development explain individual differences in executive function (Cui et al., 2020) and positive psychosis spectrum symptoms (Parkes, Moore, Calkins, Cieslak, et al., 2021); and how variations in dopamine and serotonin receptor function (either by natural biology or by drug) alter the ease versus difficulty of reaching particular brain and cognitive 
states (Braun et al., 2021; Singleton et al., 2021). The approach is absolutely germane to the understanding of neurodevelopmental differences, as it provides an explicit formal link between brain network organization and system function as evinced by dynamical transitions in state with relevance to behaviour.

\section{Emergence across time}

To complement the expansion from region to network, we now turn to questions posed by the fact that brain, behaviour, environment, and their interrelations change over a range of timescales from moments to years. Precisely how do neurodevelopmental differences reflect emergent properties of the system organising itself across developmental time according to different underlying constraints? What tools are available to study these dynamics? One particularly powerful approach is known as normative modelling, which maps the typical (or "normative") developmental trajectory, function, or curve of a brain feature (Marquand et al., 2016), and then measures how single individuals diverge from that curve (Wolfers et al., 2018, 2020; Zabihi et al., 2019). The approach has been used to map the heterogeneous phenotypes of schizophrenia, bipolar disorder, ADHD, and autism (Wolfers et al., 2018, 2020; Zabihi et al., 2019). Applying this approach to transdiagnostic dimensions of psychopathology, recent work has further shown that modelling cortical brain features as deviations from normative neurodevelopment improves prediction of psychiatric symptoms in out-of-sample testing (Parkes, Moore, Calkins, Cook, et al., 2021). Importantly, more generally deviations can also take the form of acceleration or delay of 'typical' development, which can be explained by a variety of factors including socioeconomic status (Tooley et al., 2021). 


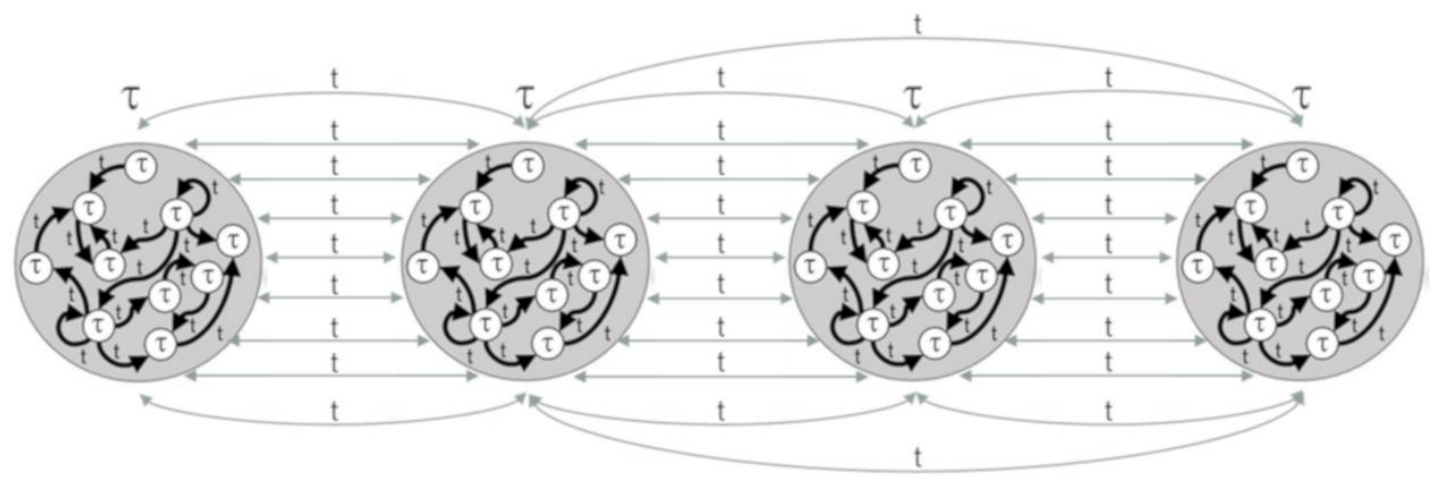

Cognition

(e.g. language, memory, attention, decision making)
Brain

(e.g. regions, tracts, neurotransmitters
Behaviour

(e.g. social interaction, conduct)

\section{Environment}

(e.g. social context, linguistic input, stimulation)

Figure 4: The network of networks. A depiction of the interconnectedness both within and across levels of analysis. The principle challenge of studying neurodevelopment, and the differences therein, is to understand how the system organises itself at one particular level, and how deviations within that level can influence, and be influenced by, emerging organisation at different levels.

Now, how do we expand beyond a single factor whose normative trajectory can be modelled, and instead understand how advance, delay, or deviation in one factor might change the possible trajectories of another factor? Gaining such an understanding is further complicated by the fact that inter-factor dependencies arise bidirectionally in time (Figure 4). For example, we know that changes in brain structure can drive changes in brain function, just as changes in brain function can drive changes in brain structure. Similarly, changes in function can drive changes in gene expression, just as changes in gene expression can drive changes in function. Changes in the environment can alter one's experiences-and by extension-neural representations and adaptations, just as changes in neurodevelopment can alter the way in which on engages with the environment-and by extension-one's experiences. These complex bidirectional relationships call for approaches that embrace the time-dependent nature of interconnections both within and between brain, behaviour, and environment. In the parlance of network science, the question is one of understanding a dynamic network of networks, and expanding impulse response and network control approaches to this fuller picture. 


\section{Conclusion}

A transdiagnostic perspective has the potential to deliver a fundamental overhaul of study design, recruitment, assessment and analysis. The aim is achieve samples that better reflect the lived reality of neurodivergent young people, rather than the reductive focus on diagnostic entities. However, we should regard this as merely the first step for a transdiagnostic approach. The end goal is to incorporate the developmental dynamics that capture how differences emerge. We need an analytic toolkit that is equal to these ambitions. There is greater potential for fundamental advances in our understanding of neurodevelopmental differences with a tighter coupling between our conceptual and methodological frameworks; if our methods are only able to capture simple relationships, at isolated moments in time, then our theories will be similarly constrained. 


\section{References}

American Psychiatric Association. (2013). Diagnostic and statistical manual of mental disorders (5th ed.). https://doi.org/10.1176/appi.books.9780890425596

Akarca, D., Vértes, P. E., Bullmore, E. T., \& Astle, D. E. (2021). A generative network model of neurodevelopmental diversity in structural brain organization. Nature Communications, 12(1), 4216. https://doi.org/10.1038/s41467-021-24430-z

Amico, F., Stauber, J., Koutsouleris, N., \& Frodl, T. (2011). Anterior cingulate cortex gray matter abnormalities in adults with attention deficit hyperactivity disorder: A voxel-based morphometry study. Psychiatry Research, 191(1), 31-35.

https://doi.org/10.1016/j.pscychresns.2010.08.011

Archibald, L. M. D., Cardy, J. O., Joanisse, M. F., \& Ansari, D. (2013). Language, Reading, and Math Learning Profiles in an Epidemiological Sample of School Age Children. PLOS ONE, 8(10), e77463. https://doi.org/10.1371/journal.pone.0077463

Astle, D. E., Bathelt, J., \& Holmes, J. (2019). Remapping the cognitive and neural profiles of children who struggle at school. Developmental Science, 22(1), e12747. https://doi.org/10.1111/desc.12747

Astle, D. E., \& Fletcher-Watson, S. (2020). Beyond the Core-Deficit Hypothesis in Developmental Disorders. Current Directions in Psychological Science, 29(5), 431-437. https://doi.org/10.1177/0963721420925518

Astle, D. E., Holmes, J., Kievit, R., \& Gathercole, S. E. (2021). Annual Research Review: The transdiagnostic revolution in neurodevelopmental disorders. Journal of Child Psychology and Psychiatry. https://doi.org/10.1111/jcpp.13481

Baron-Cohen, S. (1995). Mindblindness: An essay on autism and theory of mind. (pp. xxii, 171). The MIT Press.

Bassett, D. S., \& Gazzaniga, M. S. (2011). Understanding complexity in the human brain. Trends in Cognitive Sciences, 15(5), 200-209. https://doi.org/10.1016/j.tics.2011.03.006 
Bathelt, J., Holmes, J., \& Astle, D. E. (2018). Data-Driven Subtyping of Executive Function-Related Behavioral Problems in Children. Journal of the American Academy of Child and Adolescent Psychiatry, 57(4), 252-262.e4. https://doi.org/10.1016/j.jaac.2018.01.014

Bathelt, J., Vignoles, A., \& Astle, D. E. (2021). Just a phase? Mapping the transition of behavioural problems from childhood to adolescence. Social Psychiatry and Psychiatric Epidemiology, 56(5), 821-836. https://doi.org/10.1007/s00127-020-02014-4

Betzel, R. F., Avena-Koenigsberger, A., Goñi, J., He, Y., de Reus, M. A., Griffa, A., Vértes, P. E., Mišic, B., Thiran, J.-P., Hagmann, P., van den Heuvel, M., Zuo, X.-N., Bullmore, E. T., \& Sporns, O. (2016). Generative models of the human connectome. Neurolmage, 124(Pt A), 1054-1064. https://doi.org/10.1016/j.neuroimage.2015.09.041

Betzel, R. F., \& Bassett, D. S. (2017). Generative models for network neuroscience: Prospects and promise. Journal of The Royal Society Interface, 14(136), 20170623. https://doi.org/10.1098/rsif.2017.0623

Bishop, D. V. (1997). Cognitive neuropsychology and developmental disorders: Uncomfortable bedfellows. The Quarterly Journal of Experimental Psychology. A, Human Experimental Psychology, 50(4), 899-923. https://doi.org/10.1080/713755740

Bishop, D. V. M., \& Norbury, C. F. (2002). Exploring the borderlands of autistic disorder and specific language impairment: A study using standardised diagnostic instruments. Journal of Child Psychology and Psychiatry, and Allied Disciplines, 43(7), 917-929. https://doi.org/10.1111/1469-7610.00114

Blaauw, F. J., van der Krieke, L., Emerencia, A. C., Aiello, M., \& de Jonge, P. (2017). Personalized advice for enhancing well-being using automated impulse response analysis-AIRA. ArXiv:1706.09268 [Cs]. http://arxiv.org/abs/1706.09268

Bos, F. M., Blaauw, F. J., Snippe, E., van der Krieke, L., de Jonge, P., \& Wichers, M. (2018). Exploring the emotional dynamics of subclinically depressed individuals with and without anhedonia: 
An experience sampling study. Journal of Affective Disorders, 228, 186-193.

https://doi.org/10.1016/j.jad.2017.12.017

Boxhoorn, S., Lopez, E., Schmidt, C., Schulze, D., Hänig, S., \& Freitag, C. M. (2018). Attention profiles in autism spectrum disorder and subtypes of attention-deficit/hyperactivity disorder. European Child \& Adolescent Psychiatry, 27(11), 1433-1447. https://doi.org/10.1007/s00787-018-1138-8

Brandmaier, A. M., von Oertzen, T., McArdle, J. J., \& Lindenberger, U. (2013). Structural equation model trees. Psychological Methods, 18(1), 71-86. https://doi.org/10.1037/a0030001 Braun, U., Harneit, A., Pergola, G., Menara, T., Schäfer, A., Betzel, R. F., Zang, Z., Schweiger, J. I., Zhang, X., Schwarz, K., Chen, J., Blasi, G., Bertolino, A., Durstewitz, D., Pasqualetti, F., Schwarz, E., Meyer-Lindenberg, A., Bassett, D. S., \& Tost, H. (2021). Brain network dynamics during working memory are modulated by dopamine and diminished in schizophrenia. Nature Communications, 12(1), 3478. https://doi.org/10.1038/s41467-021-23694-9

Bull, R., Espy, K. A., \& Wiebe, S. A. (2008). Short-Term Memory, Working Memory, and Executive Functioning in Preschoolers: Longitudinal Predictors of Mathematical Achievement at Age 7 Years. Developmental Neuropsychology, 33(3), 205-228. https://doi.org/10.1080/87565640801982312

Bullmore, E., Barnes, A., Bassett, D. S., Fornito, A., Kitzbichler, M., Meunier, D., \& Suckling, J. (2009). Generic aspects of complexity in brain imaging data and other biological systems. Neurolmage, 47(3), 1125-1134. https://doi.org/10.1016/j.neuroimage.2009.05.032

Burnett Heyes, S., Zokaei, N., van der Staaij, I., Bays, P. M., \& Husain, M. (2012). Development of visual working memory precision in childhood. Developmental Science, 15(4), 528-539. https://doi.org/10.1111/j.1467-7687.2012.01148.x

Caspi, A., Houts, R. M., Ambler, A., Danese, A., Elliott, M. L., Hariri, A., Harrington, H., Hogan, S., Poulton, R., Ramrakha, S., Rasmussen, L. J. H., Reuben, A., Richmond-Rakerd, L., Sugden, K., Wertz, J., Williams, B. S., \& Moffitt, T. E. (2020). Longitudinal Assessment of Mental Health 
Disorders and Comorbidities Across 4 Decades Among Participants in the Dunedin Birth Cohort Study. JAMA Network Open, 3(4), e203221. https://doi.org/10.1001/jamanetworkopen.2020.3221

Caspi, A., Houts, R. M., Belsky, D. W., Goldman-Mellor, S. J., Harrington, H., Israel, S., Meier, M. H., Ramrakha, S., Shalev, I., Poulton, R., \& Moffitt, T. E. (2014). The p Factor: One General Psychopathology Factor in the Structure of Psychiatric Disorders? Clinical Psychological Science : A Journal of the Association for Psychological Science, 2(2), 119-137. https://doi.org/10.1177/2167702613497473

Cepeda, N. J., Kramer, A. F., \& Gonzalez de Sather, J. C. (2001). Changes in executive control across the life span: Examination of task-switching performance. Developmental Psychology, 37(5), 715-730.

Chapman, R. (2020). Neurodiversity, disability, wellbeing. In Neurodiversity Studies. Routledge.

Chen, Y.-W., Cordier, R., \& Brown, N. (2015). A preliminary study on the reliability and validity of using experience sampling method in children with autism spectrum disorders. Developmental Neurorehabilitation, 18(6), 383-389. https://doi.org/10.3109/17518423.2013.855274

Chu-Shore, C. J., Kramer, M. A., Bianchi, M. T., Caviness, V. S., \& Cash, S. S. (2011). Network analysis: Applications for the developing brain. Journal of Child Neurology, 26(4), 488-500. https://doi.org/10.1177/0883073810385345

Cicchetti, D., \& Rogosch, F. A. (1996). Equifinality and multifinality in developmental psychopathology. Development and Psychopathology, 8(4), 597-600. https://doi.org/10.1017/S0954579400007318

Coghill, D., \& Sonuga-Barke, E. J. S. (2012). Annual research review: Categories versus dimensions in the classification and conceptualisation of child and adolescent mental disorders-implications of recent empirical study. Journal of Child Psychology and Psychiatry, and Allied Disciplines, 53(5), 469-489. https://doi.org/10.1111/j.1469-7610.2011.02511.x 
Cornblath, E. J., Mahadevan, A., He, X., Ruparel, K., Lydon-Staley, D. M., Moore, T. M., Gur, R. C., Zackai, E. H., Emanuel, B., McDonald-McGinn, D. M., Wolf, D. H., Satterthwaite, T. D., Roalf, D. R., Gur, R. E., \& Bassett, D. S. (2021). Altered functional brain dynamics in chromosome 22q11.2 deletion syndrome during facial affect processing. Molecular Psychiatry, 1-9. https://doi.org/10.1038/s41380-021-01302-y

Cornelius, S. P., Kath, W. L., \& Motter, A. E. (2013). Realistic control of network dynamics. Nature Communications, 4(1), 1942. https://doi.org/10.1038/ncomms2939

Cortese, S., Aoki, Y. Y., Itahashi, T., Castellanos, F. X., \& Eickhoff, S. B. (2021). Systematic Review and Meta-analysis: Resting-State Functional Magnetic Resonance Imaging Studies of AttentionDeficit/Hyperactivity Disorder. Journal of the American Academy of Child \& Adolescent Psychiatry, 60(1), 61-75. https://doi.org/10.1016/j.jaac.2020.08.014

Cragg, L., Fox, A., Nation, K., Reid, C., \& Anderson, M. (2009). Neural correlates of successful and partial inhibitions in children: An ERP study. Developmental Psychobiology, 51(7), 533-543. https://doi.org/10.1002/dev.20391

Cragg, L., \& Nation, K. (2008). Go or no-go? Developmental improvements in the efficiency of response inhibition in mid-childhood. Developmental Science, 11(6), 819-827. https://doi.org/10.1111/j.1467-7687.2008.00730.x

Cui, Z., Stiso, J., Baum, G. L., Kim, J. Z., Roalf, D. R., Betzel, R. F., Gu, S., Lu, Z., Xia, C. H., He, X., Ciric, R., Oathes, D. J., Moore, T. M., Shinohara, R. T., Ruparel, K., Davatzikos, C., Pasqualetti, F., Gur, R. E., Gur, R. C., ... Satterthwaite, T. D. (2020). Optimization of energy state transition trajectory supports the development of executive function during youth. ELife, 9, e53060. https://doi.org/10.7554/eLife.53060

Dalmaijer, E. S., Gibbons, S. G., Bignardi, G., Anwyl-Irvine, A. L., Siugzdaite, R., Smith, T. A., Uh, S., Johnson, A., \& Astle, D. E. (2021). Direct and indirect links between children's socioeconomic status and education: Pathways via mental health, attitude, and cognition. Current Psychology. https://doi.org/10.1007/s12144-021-02232-2 
de Boo, G. M., \& Prins, P. J. M. (2007). Social incompetence in children with ADHD: Possible moderators and mediators in social-skills training. Clinical Psychology Review, 27(1), 78-97. https://doi.org/10.1016/j.cpr.2006.03.006

de Zwart, J. A., Silva, A. C., van Gelderen, P., Kellman, P., Fukunaga, M., Chu, R., Koretsky, A. P., Frank, J. A., \& Duyn, J. H. (2005). Temporal dynamics of the BOLD fMRI impulse response. Neurolmage, 24(3), 667-677. https://doi.org/10.1016/j.neuroimage.2004.09.013

Dirlikov, B., Shiels Rosch, K., Crocetti, D., Denckla, M. B., Mahone, E. M., \& Mostofsky, S. H. (2015). Distinct frontal lobe morphology in girls and boys with ADHD. Neurolmage. Clinical, 7, 222229. https://doi.org/10.1016/j.nicl.2014.12.010

Elliott, M. L., Knodt, A. R., Ireland, D., Morris, M. L., Poulton, R., Ramrakha, S., Sison, M. L., Moffitt, T. E., Caspi, A., \& Hariri, A. R. (2020). What Is the Test-Retest Reliability of Common TaskFunctional MRI Measures? New Empirical Evidence and a Meta-Analysis. Psychological Science, 31(7), 792-806. https://doi.org/10.1177/0956797620916786

Enkavi, A. Z., Eisenberg, I. W., Bissett, P. G., Mazza, G. L., MacKinnon, D. P., Marsch, L. A., \& Poldrack, R. A. (2019). Large-scale analysis of test-retest reliabilities of self-regulation measures. Proceedings of the National Academy of Sciences, 116(12), 5472-5477. https://doi.org/10.1073/pnas.1818430116

Fair, D. A., Dosenbach, N. U. F., Church, J. A., Cohen, A. L., Brahmbhatt, S., Miezin, F. M., Barch, D. M., Raichle, M. E., Petersen, S. E., \& Schlaggar, B. L. (2007). Development of distinct control networks through segregation and integration. Proceedings of the National Academy of Sciences of the United States of America, 104(33), 13507-13512. https://doi.org/10.1073/pnas.0705843104

Fisher, A. J., Reeves, J. W., Lawyer, G., Medaglia, J. D., \& Rubel, J. A. (2017). Exploring the idiographic dynamics of mood and anxiety via network analysis. Journal of Abnormal Psychology, 126(8), 1044-1056. https://doi.org/10.1037/abn0000311 
Frodl, T., \& Skokauskas, N. (2012). Meta-analysis of structural MRI studies in children and adults with attention deficit hyperactivity disorder indicates treatment effects. Acta Psychiatrica Scandinavica, 125(2), 114-126. https://doi.org/10.1111/j.1600-0447.2011.01786.x

Fröhner, J. H., Teckentrup, V., Smolka, M. N., \& Kroemer, N. B. (2019). Addressing the reliability fallacy in fMRI: Similar group effects may arise from unreliable individual effects. Neurolmage, 195, 174-189. https://doi.org/10.1016/j.neuroimage.2019.03.053

Fuhrmann, D., Knoll, L. J., \& Blakemore, S.-J. (2015). Adolescence as a Sensitive Period of Brain Development. Trends in Cognitive Sciences, 19(10), 558-566. https://doi.org/10.1016/j.tics.2015.07.008

Gathercole, S. E., Pickering, S. J., Ambridge, B., \& Wearing, H. (2004). The structure of working memory from 4 to 15 years of age. Developmental Psychology, 40(2), 177-190. https://doi.org/10.1037/0012-1649.40.2.177

Goghari, V. M., Sanford, N., Spilka, M. J., \& Woodward, T. S. (2017). Task-Related Functional Connectivity Analysis of Emotion Discrimination in a Family Study of Schizophrenia. Schizophrenia Bulletin, 43(6), 1348-1362. https://doi.org/10.1093/schbul/sbx004

Gottlieb, G. (2007). Probabilistic epigenesis. Developmental Science, 10(1), 1-11. https://doi.org/10.1111/j.1467-7687.2007.00556.x

Gottlieb, G. (2022). Handbook of Developmental Psychology (By pages 3-17). SAGE Publications Ltd. https://doi.org/10.4135/9781848608306

Greven, C. U., Bralten, J., Mennes, M., O’Dwyer, L., van Hulzen, K. J. E., Rommelse, N., Schweren, L. J. S., Hoekstra, P. J., Hartman, C. A., Heslenfeld, D., Oosterlaan, J., Faraone, S. V., Franke, B., Zwiers, M. P., Arias-Vasquez, A., \& Buitelaar, J. K. (2015). Developmentally stable wholebrain volume reductions and developmentally sensitive caudate and putamen volume alterations in those with attention-deficit/hyperactivity disorder and their unaffected siblings. JAMA Psychiatry, 72(5), 490-499. https://doi.org/10.1001/jamapsychiatry.2014.3162 
Happé, F., Ronald, A., \& Plomin, R. (2006). Time to give up on a single explanation for autism. Nature Neuroscience, 9(10), 1218-1220. https://doi.org/10.1038/nn1770

Hartung, J., Doebler, P., Schroeders, U., \& Wilhelm, O. (2018). Dedifferentiation and differentiation of intelligence in adults across age and years of education. Intelligence, 69, 37-49. https://doi.org/10.1016/j.intell.2018.04.003

Haslam, N., Williams, B., Prior, M., Haslam, R., Graetz, B., \& Sawyer, M. (2006). The latent structure of attention-deficit/hyperactivity disorder: A taxometric analysis. The Australian and New Zealand Journal of Psychiatry, 40(8), 639-647. https://doi.org/10.1080/j.14401614.2006.01863.x

Hauser, T. U., lannaccone, R., Ball, J., Mathys, C., Brandeis, D., Walitza, S., \& Brem, S. (2014). Role of the Medial Prefrontal Cortex in Impaired Decision Making in Juvenile AttentionDeficit/Hyperactivity Disorder. JAMA Psychiatry, 71(10), 1165-1173. https://doi.org/10.1001/jamapsychiatry.2014.1093

Hawkins, E., Gathercole, S., Astle, D., The CALM Team, \& Holmes, J. (2016). Language Problems and ADHD Symptoms: How Specific Are the Links? Brain Sciences, 6(4), 50. https://doi.org/10.3390/brainsci6040050

Holmes, J., Bryant, A., Gathercole, S. E., \& the CALM Team. (2019). Protocol for a transdiagnostic study of children with problems of attention, learning and memory (CALM). BMC Pediatrics, 19(1), 10. https://doi.org/10.1186/s12887-018-1385-3

Holmes, J., Butterfield, S., Cormack, F., van Loenhoud, A., Ruggero, L., Kashikar, L., \& Gathercole, S. (2015). Improving working memory in children with low language abilities. Frontiers in Psychology, 6, 519. https://doi.org/10.3389/fpsyg.2015.00519

Holmes, J., Guy, J., Kievit, R. A., Bryant, A., Mareva, S., CALM Team, \& Gathercole, S. E. (2021). Cognitive dimensions of learning in children with problems in attention, learning, and memory. Journal of Educational Psychology, 113(7), 1454-1480. https://doi.org/10.1037/edu0000644 
Holmes, J., Mareva, S., Bennett, M. P., Black, M. J., \& Guy, J. (2021). Higher-order dimensions of psychopathology in a neurodevelopmental transdiagnostic sample. Journal of Abnormal Psychology, 130(8), 909-922. https://doi.org/10.1037/abn0000710

Howe, E., Bosley, H. G., \& Fisher, A. J. (2020). Idiographic network analysis of discrete mood states prior to treatment. Counselling and Psychotherapy Research, 20(3), 470-478. https://doi.org/10.1002/capr.12295

Hulme, C., \& Snowling, M. J. (2013). Developmental Disorders of Language Learning and Cognition. John Wiley \& Sons.

Johnson, M. H. (2000). Functional brain development in infants: Elements of an interactive specialization framework. Child Development, 71(1), 75-81. https://doi.org/10.1111/14678624.00120

Johnson, M. H. (2011). Interactive Specialization: A domain-general framework for human functional brain development? Developmental Cognitive Neuroscience, 1(1), 7-21. https://doi.org/10.1016/j.den.2010.07.003

Jones, J. S., Team, T. C., \& Astle, D. E. (n.d.). Segregation and integration of the functional connectome in neurodevelopmentally 'at risk' children. Developmental Science, $n / a(n / a)$, e13209. https://doi.org/10.1111/desc.13209

Kaiser, M., \& Hilgetag, C. C. (2004). Modelling the development of cortical systems networks. Neurocomputing, 58-60, 297-302. https://doi.org/10.1016/j.neucom.2004.01.059 Karcher, N. R., \& Barch, D. M. (2021). The ABCD study: Understanding the development of risk for mental and physical health outcomes. Neuropsychopharmacology, 46(1), 131-142. https://doi.org/10.1038/s41386-020-0736-6

Karmiloff-Smith, A. (2009). Nativism versus neuroconstructivism: Rethinking the study of developmental disorders. Developmental Psychology, 45(1), 56-63. https://doi.org/10.1037/a0014506 
Karmiloff-Smith, A. (2010). Neuroimaging of the developing brain: Taking "developing" seriously. Human Brain Mapping, 31(6), 934-941. https://doi.org/10.1002/hbm.21074

Karmiloff-Smith, B. A. (1994). Beyond Modularity: A Developmental Perspective on Cognitive Science. European Journal of Disorders of Communication, 29(1), 95-105. https://doi.org/10.3109/13682829409041485

Kernbach, J. M., Satterthwaite, T. D., Bassett, D. S., Smallwood, J., Margulies, D., Krall, S., Shaw, P., Varoquaux, G., Thirion, B., Konrad, K., \& Bzdok, D. (2018). Shared endo-phenotypes of default mode dysfunction in attention deficit/hyperactivity disorder and autism spectrum disorder. Translational Psychiatry, 8(1), 1-11. https://doi.org/10.1038/s41398-018-0179-6

Kessler, R. C., McLaughlin, K. A., Green, J. G., Gruber, M. J., Sampson, N. A., Zaslavsky, A. M., AguilarGaxiola, S., Alhamzawi, A. O., Alonso, J., Angermeyer, M., Benjet, C., Bromet, E., Chatterji, S., de Girolamo, G., Demyttenaere, K., Fayyad, J., Florescu, S., Gal, G., Gureje, O., ... Williams, D. R. (2010). Childhood adversities and adult psychopathology in the WHO World Mental Health Surveys. The British Journal of Psychiatry, 197(5), 378-385. https://doi.org/10.1192/bjp.bp.110.080499

Kievit, R. A., Davis, S. W., Griffiths, J., Correia, M. M., Cam-Can, null, \& Henson, R. N. (2016). A watershed model of individual differences in fluid intelligence. Neuropsychologia, 91, 186198. https://doi.org/10.1016/j.neuropsychologia.2016.08.008

Kotov, R., Krueger, R. F., Watson, D., Achenbach, T. M., Althoff, R. R., Bagby, R. M., Brown, T. A., Carpenter, W. T., Caspi, A., Clark, L. A., Eaton, N. R., Forbes, M. K., Forbush, K. T., Goldberg, D., Hasin, D., Hyman, S. E., Ivanova, M. Y., Lynam, D. R., Markon, K., ... Zimmerman, M. (2017). The Hierarchical Taxonomy of Psychopathology (HiTOP): A dimensional alternative to traditional nosologies. Journal of Abnormal Psychology, 126(4), 454-477. https://doi.org/10.1037/abn0000258 
Kovac, M., Mosner, M., Miller, S., Hanna, E. K., \& Dichter, G. S. (2016). Experience Sampling of Positive Affect in Adolescents with Autism: Feasibility and Preliminary Findings. Research in Autism Spectrum Disorders, 29-30, 57-65. https://doi.org/10.1016/j.rasd.2016.06.003

Kowalczyk, O. S., Mehta, M. A., O’Daly, O. G., \& Criaud, M. (2021). Task-Based Functional Connectivity in Attention-Deficit/Hyperactivity Disorder: A Systematic Review. Biological Psychiatry Global Open Science. https://doi.org/10.1016/j.bpsgos.2021.10.006

Kushki, A., Anagnostou, E., Hammill, C., Duez, P., Brian, J., laboni, A., Schachar, R., Crosbie, J., Arnold, P., \& Lerch, J. P. (2019). Examining overlap and homogeneity in ASD, ADHD, and OCD: A data-driven, diagnosis-agnostic approach. Translational Psychiatry, 9(1), 1-11. https://doi.org/10.1038/s41398-019-0631-2

Lawson, R. P., Mathys, C., \& Rees, G. (2017). Adults with autism overestimate the volatility of the sensory environment. Nature Neuroscience, 20(9), 1293-1299. https://doi.org/10.1038/nn.4615

Leonard, J. A., Lydon-Staley, D. M., Sharp, S. D. S., Liu, H. Z., Park, A. T., Bassett, D. S., Duckworth, A. L., \& Mackey, A. P. (2021). Daily fluctuations in young children's persistence. Child Development. https://doi.org/10.1111/cdev.13717

Lessov-Schlaggar, C. N., Rubin, J. B., \& Schlaggar, B. L. (2016). The Fallacy of Univariate Solutions to Complex Systems Problems. Frontiers in Neuroscience, 10. https://www.frontiersin.org/article/10.3389/fnins.2016.00267

Levy, Y., \& Ebstein, R. P. (2009). Research review: Crossing syndrome boundaries in the search for brain endophenotypes. Journal of Child Psychology and Psychiatry, and Allied Disciplines, 50(6), 657-668. https://doi.org/10.1111/j.1469-7610.2008.01986.x

Liu, Y.-Y., Slotine, J.-J., \& Barabási, A.-L. (2011). Controllability of complex networks. Nature, 473(7346), 167-173. https://doi.org/10.1038/nature10011 
Lydon-Staley, D. M., Barnett, I., Satterthwaite, T. D., \& Bassett, D. S. (2019). Digital phenotyping for psychiatry: Accommodating data and theory with network science methodologies. Current Opinion in Biomedical Engineering, 9, 8-13. https://doi.org/10.1016/j.cobme.2018.12.003

Lydon-Staley, D. M., Cornblath, E. J., Blevins, A. S., \& Bassett, D. S. (2021). Modeling brain, symptom, and behavior in the winds of change. Neuropsychopharmacology, 46(1), 20-32. https://doi.org/10.1038/s41386-020-00805-6

Lydon-Staley, D. M., Leventhal, A. M., Piper, M. E., Schnoll, R. A., \& Bassett, D. S. (2021). Temporal networks of tobacco withdrawal symptoms during smoking cessation treatment. Journal of Abnormal Psychology, 130(1), 89-101. https://doi.org/10.1037/abn0000650

Lydon-Staley, D. M., Zurn, P., \& Bassett, D. S. (2020). Within-person variability in curiosity during daily life and associations with well-being. Journal of Personality, 88(4), 625-641. https://doi.org/10.1111/jopy.12515

Lynn, C. W., \& Bassett, D. S. (2019). The physics of brain network structure, function and control. Nature Reviews Physics, 1(5), 318-332. https://doi.org/10.1038/s42254-019-0040-8 Mackie, S., Shaw, P., Lenroot, R., Pierson, R., Greenstein, D. K., Nugent, T. F., Sharp, W. S., Giedd, J. N., \& Rapoport, J. L. (2007). Cerebellar development and clinical outcome in attention deficit hyperactivity disorder. The American Journal of Psychiatry, 164(4), 647-655. https://doi.org/10.1176/ajp.2007.164.4.647

Mahone, E. M., Ranta, M. E., Crocetti, D., O’Brien, J., Kaufmann, W. E., Denckla, M. B., \& Mostofsky, S. H. (2011). Comprehensive Examination of Frontal Regions in Boys and Girls with Attention-Deficit/Hyperactivity Disorder. Journal of the International Neuropsychological Society : JINS, 17(6), 1047-1057. https://doi.org/10.1017/S1355617711001056

Majerus, S., \& Cowan, N. (2016). The Nature of Verbal Short-Term Impairment in Dyslexia: The Importance of Serial Order. Frontiers in Psychology, 7, 1522.

https://doi.org/10.3389/fpsyg.2016.01522 
Marek, S., Tervo-Clemmens, B., Calabro, F., Montez, D., Kay, B., Hatoum, A., Donohue, M. R., Foran, W., Miller, R., Feczko, E., Miranda-Dominguez, O., Graham, A., Earl, E., Perrone, A., Cordova, M., Doyle, O., Moore, L., Conan, G., Uriarte, J., ... Dosenbach, N. U. F. (2020). Towards Reproducible Brain-Wide Association Studie. https://doi.org/10.1101/2020.08.21.257758

Marquand, A. F., Rezek, I., Buitelaar, J., \& Beckmann, C. F. (2016). Understanding Heterogeneity in Clinical Cohorts Using Normative Models: Beyond Case-Control Studies. Biological Psychiatry, 80(7), 552-561. https://doi.org/10.1016/j.biopsych.2015.12.023

McGlothlin, A. E., \& Viele, K. (2018). Bayesian Hierarchical Models. JAMA, 320(22), 2365-2366. https://doi.org/10.1001/jama.2018.17977

McGorry, P. D., \& Mei, C. (2021). Clinical Staging for Youth Mental Disorders: Progress in Reforming Diagnosis and Clinical Care. Annual Review of Developmental Psychology, 3(1), 15-39. https://doi.org/10.1146/annurev-devpsych-050620-030405

McGowan, A. L., Falk, E. B., Zurn, P., Bassett, D. S., \& Lydon-Staley, D. M. (2022). Daily sensationseeking and urgency in young adults: Examining associations with alcohol use and selfdefined risky behaviors. Addictive Behaviors, 127, 107219. https://doi.org/10.1016/j.addbeh.2021.107219

Newman, M. E. J. (2010). Networks: An introduction. Oxford University Press; /z-wcorg/. Norrman, G., \& Bylund, E. (2016). The irreversibility of sensitive period effects in language development: Evidence from second language acquisition in international adoptees. Developmental Science, 19(3), 513-520. https://doi.org/10.1111/desc.12332

Onnink, A. M. H., Zwiers, M. P., Hoogman, M., Mostert, J. C., Kan, C. C., Buitelaar, J., \& Franke, B. (2014). Brain alterations in adult ADHD: Effects of gender, treatment and comorbid depression. European Neuropsychopharmacology: The Journal of the European College of Neuropsychopharmacology, 24(3), 397-409. https://doi.org/10.1016/j.euroneuro.2013.11.011 
Parkes, L., Moore, T. M., Calkins, M. E., Cieslak, M., Roalf, D. R., Wolf, D. H., Gur, R. C., Gur, R. E., Satterthwaite, T. D., \& Bassett, D. S. (2021). Network Controllability in Transmodal Cortex Predicts Positive Psychosis Spectrum Symptoms. Biological Psychiatry, 90(6), 409-418. https://doi.org/10.1016/j.biopsych.2021.03.016

Parkes, L., Moore, T. M., Calkins, M. E., Cook, P. A., Cieslak, M., Roalf, D. R., Wolf, D. H., Gur, R. C., Gur, R. E., Satterthwaite, T. D., \& Bassett, D. S. (2021). Transdiagnostic dimensions of psychopathology explain individuals' unique deviations from normative neurodevelopment in brain structure. Translational Psychiatry, 11(1), 232. https://doi.org/10.1038/s41398-02101342-6

Parkes, L., Satterthwaite, T. D., \& Bassett, D. S. (2020). Towards precise resting-state fMRI biomarkers in psychiatry: Synthesizing developments in transdiagnostic research, dimensional models of psychopathology, and normative neurodevelopment. Current Opinion in Neurobiology, 65, 120-128. https://doi.org/10.1016/j.conb.2020.10.016

Parsons, S., Kruijt, A.-W., \& Fox, E. (2019). Psychological Science Needs a Standard Practice of Reporting the Reliability of Cognitive-Behavioral Measurements. Advances in Methods and Practices in Psychological Science, 2(4), 378-395.

https://doi.org/10.1177/2515245919879695

Pasqualetti, F., Zampieri, S., \& Bullo, F. (2014). Controllability Metrics, Limitations and Algorithms for Complex Networks. ArXiv:1308.1201 [Physics]. http://arxiv.org/abs/1308.1201

Pennington, B. F. (2006). From single to multiple deficit models of developmental disorders. Cognition, 101(2), 385-413. https://doi.org/10.1016/j.cognition.2006.04.008

Pennington, B. F., \& Ozonoff, S. (1996). Executive functions and developmental psychopathology. Journal of Child Psychology and Psychiatry, and Allied Disciplines, 37(1), 51-87. https://doi.org/10.1111/j.1469-7610.1996.tb01380.x 
Piccirillo, M. L., \& Rodebaugh, T. L. (2019). Foundations of idiographic methods in psychology and applications for psychotherapy. Clinical Psychology Review, 71, 90-100. https://doi.org/10.1016/j.cpr.2019.01.002

Psychiatry Online. (n.d.). DSM Library. Retrieved February 28, 2022, from https://dsm.psychiatryonline.org/doi/abs/10.1176/appi.books.9780890425596

Rubinov, M., \& Sporns, O. (2010). Complex network measures of brain connectivity: Uses and interpretations. Neurolmage, 52(3), 1059-1069. https://doi.org/10.1016/j.neuroimage.2009.10.003

Ruggero, C. J., Kotov, R., Hopwood, C. J., First, M., Clark, L. A., Skodol, A. E., Mullins-Sweatt, S. N., Patrick, C. J., Bach, B., Cicero, D. C., Docherty, A., Simms, L. J., Bagby, R. M., Krueger, R. F., Callahan, J. L., Chmielewski, M., Conway, C. C., De Clercq, B., Dornbach-Bender, A., ... Zimmermann, J. (2019). Integrating the Hierarchical Taxonomy of Psychopathology (HiTOP) into clinical practice. Journal of Consulting and Clinical Psychology, 87(12), 1069-1084. https://doi.org/10.1037/ccp0000452

Ruths, J., \& Ruths, D. (2014). Control Profiles of Complex Networks. Science, 343(6177), 1373-1376. https://doi.org/10.1126/science.1242063

Sanford, N., Whitman, J. C., \& Woodward, T. S. (2020). Task-merging for finer separation of functional brain networks in working memory. Cortex; a Journal Devoted to the Study of the Nervous System and Behavior, 125, 246-271. https://doi.org/10.1016/j.cortex.2019.12.014 Sayal, K., Prasad, V., Daley, D., Ford, T., \& Coghill, D. (2018). ADHD in children and young people: Prevalence, care pathways, and service provision. The Lancet. Psychiatry, 5(2), 175-186. https://doi.org/10.1016/S2215-0366(17)30167-0

Scahill, L., \& Schwab-Stone, M. (2000). Epidemiology of Adhd in School-Age Children. Child and Adolescent Psychiatric Clinics of North America, 9(3), 541-555. https://doi.org/10.1016/S1056-4993(18)30106-8 
Shapiro, E. (2014). Correcting the bias against interdisciplinary research. ELife, 3, e02576. https://doi.org/10.7554/eLife.02576

Shaw, P., Lerch, J., Greenstein, D., Sharp, W., Clasen, L., Evans, A., Giedd, J., Castellanos, F. X., \& Rapoport, J. (2006). Longitudinal mapping of cortical thickness and clinical outcome in children and adolescents with attention-deficit/hyperactivity disorder. Archives of General Psychiatry, 63(5), 540-549. https://doi.org/10.1001/archpsyc.63.5.540

Shimi, A., Kuo, B.-C., Astle, D. E., Nobre, A. C., \& Scerif, G. (2014). Age group and individual differences in attentional orienting dissociate neural mechanisms of encoding and maintenance in visual STM. Journal of Cognitive Neuroscience, 26(4), 864-877. https://doi.org/10.1162/jocn_a_00526

Shimi, A., Nobre, A. C., Astle, D., \& Scerif, G. (2014). Orienting attention within visual short-term memory: Development and mechanisms. Child Development, 85(2), 578-592. https://doi.org/10.1111/cdev.12150

Simpson-Kent, I. L., Fuhrmann, D., Bathelt, J., Achterberg, J., Borgeest, G. S., \& Kievit, R. A. (2020). Neurocognitive reorganization between crystallized intelligence, fluid intelligence and white matter microstructure in two age-heterogeneous developmental cohorts. Developmental Cognitive Neuroscience, 41, 100743. https://doi.org/10.1016/j.dcn.2019.100743

Singleton, S. P., Luppi, A. I., Carhart-Harris, R. L., Cruzat, J., Roseman, L., Deco, G., Kringelbach, M. L., Stamatakis, E. A., \& Kuceyeski, A. (2021). Psychedelics Flatten the brain's energy landscape: Evidence from receptor-informed network control theory (p. 2021.05.14.444193). bioRxiv. https://doi.org/10.1101/2021.05.14.444193

Siugzdaite, R., Bathelt, J., Holmes, J., \& Astle, D. E. (2020). Transdiagnostic Brain Mapping in Developmental Disorders. Current Biology, 30(7), 1245-1257.e4. https://doi.org/10.1016/j.cub.2020.01.078 
Sonuga-Barke, E. J. S., \& Coghill, D. (2014). Editorial perspective: Laying the foundations for next generation models of ADHD neuropsychology. Journal of Child Psychology and Psychiatry, and Allied Disciplines, 55(11), 1215-1217. https://doi.org/10.1111/jcpp.12341

Sonuga-Barke, E. J. S., Cortese, S., Fairchild, G., \& Stringaris, A. (2016). Annual Research Review: Transdiagnostic neuroscience of child and adolescent mental disorders - differentiating decision making in attention-deficit/hyperactivity disorder, conduct disorder, depression, and anxiety. Journal of Child Psychology and Psychiatry, and Allied Disciplines, 57(3), 321349. https://doi.org/10.1111/jcpp.12496

Swift, V., \& Peterson, J. B. (2018). Improving the effectiveness of performance feedback by considering personality traits and task demands. PLOS ONE, 13(5), e0197810. https://doi.org/10.1371/journal.pone.0197810

Tang, E., Giusti, C., Baum, G. L., Gu, S., Pollock, E., Kahn, A. E., Roalf, D. R., Moore, T. M., Ruparel, K., Gur, R. C., Gur, R. E., Satterthwaite, T. D., \& Bassett, D. S. (2017). Developmental increases in white matter network controllability support a growing diversity of brain dynamics. Nature Communications, 8(1), 1252. https://doi.org/10.1038/s41467-017-01254-4

Tooley, U. A., Bassett, D. S., \& Mackey, A. P. (2021). Environmental influences on the pace of brain development. Nature Reviews Neuroscience, 22(6), 372-384.

https://doi.org/10.1038/s41583-021-00457-5

Vértes, P. E., Alexander-Bloch, A. F., Gogtay, N., Giedd, J. N., Rapoport, J. L., \& Bullmore, E. T. (2012). Simple models of human brain functional networks. Proceedings of the National Academy of Sciences, 109(15), 5868-5873. https://doi.org/10.1073/pnas.1111738109

Willcutt, E. G., Doyle, A. E., Nigg, J. T., Faraone, S. V., \& Pennington, B. F. (2005). Validity of the executive function theory of attention-deficit/hyperactivity disorder: A meta-analytic review. Biological Psychiatry, 57(11), 1336-1346. https://doi.org/10.1016/j.biopsych.2005.02.006 
Williams, D. L., Goldstein, G., Carpenter, P. A., \& Minshew, N. J. (2005). Verbal and spatial working memory in autism. Journal of Autism and Developmental Disorders, 35(6), 747-756. https://doi.org/10.1007/s10803-005-0021-x

Witton, C., Talcott, J. B., \& Henning, G. B. (2017). Psychophysical measurements in children: Challenges, pitfalls, and considerations. PeerJ, 5, e3231. https://doi.org/10.7717/peerj.3231

Wolfers, T., Beckmann, C. F., Hoogman, M., Buitelaar, J. K., Franke, B., \& Marquand, A. F. (2020). Individual differences v. the average patient: Mapping the heterogeneity in ADHD using normative models. Psychological Medicine, 50(2), 314-323. https://doi.org/10.1017/S0033291719000084

Wolfers, T., Doan, N. T., Kaufmann, T., Alnæs, D., Moberget, T., Agartz, I., Buitelaar, J. K., Ueland, T., Melle, I., Franke, B., Andreassen, O. A., Beckmann, C. F., Westlye, L. T., \& Marquand, A. F. (2018). Mapping the Heterogeneous Phenotype of Schizophrenia and Bipolar Disorder Using Normative Models. JAMA Psychiatry, 75(11), 1146-1155. https://doi.org/10.1001/jamapsychiatry.2018.2467

Woodward, T. S., Tipper, C. M., Leung, A. L., Lavigne, K. M., Sanford, N., \& Metzak, P. D. (2015). Reduced functional connectivity during controlled semantic integration in schizophrenia: A multivariate approach. Human Brain Mapping, 36(8), 2948-2964. https://doi.org/10.1002/hbm.22820

Yang, X., Ram, N., Lougheed, J. P., Molenaar, P. C. M., \& Hollenstein, T. (2019). Adolescents' emotion system dynamics: Network-based analysis of physiological and emotional experience. Developmental Psychology, 55(9), 1982-1993. https://doi.org/10.1037/dev0000690 Zabihi, M., Oldehinkel, M., Wolfers, T., Frouin, V., Goyard, D., Loth, E., Charman, T., Tillmann, J., Banaschewski, T., Dumas, G., Holt, R., Baron-Cohen, S., Durston, S., Bölte, S., Murphy, D., Ecker, C., Buitelaar, J. K., Beckmann, C. F., \& Marquand, A. F. (2019). Dissecting the Heterogeneous Cortical Anatomy of Autism Spectrum Disorder Using Normative Models. 
Biological Psychiatry. Cognitive Neuroscience and Neuroimaging, 4(6), 567-578.

https://doi.org/10.1016/j.bpsc.2018.11.013

Zhang, J., Kucyi, A., Raya, J., Nielsen, A. N., Nomi, J. S., Damoiseaux, J. S., Greene, D. J., Horovitz, S. G., Uddin, L. Q., \& Whitfield-Gabrieli, S. (2021). What have we really learned from functional connectivity in clinical populations? Neurolmage, 242, 118466.

https://doi.org/10.1016/j.neuroimage.2021.118466

World Health Organization. (2019). ICD-11: International classification of diseases (11th revision). Retrieved from https://icd.who.int/ 